\title{
A minimally invasive modified technique for female stress urinary incontinence: transobturator tape without paraurethral dissection
}

\author{
Özkan Onuk \\ Department of Urology, Yeniyüzyıl University, Istanbul, Turkey
}

Videosurgery Miniinv 2019; 14 (2): 278-283

DOI: https://doi.org/10.5114/wiitm.2018.77715

\begin{abstract}
Introduction: Mid-urethral slings, including transobturator tape (TOT), tension-free vaginal tape (TVT), tension-free vaginal tape-obturator (TVT-O), and a single incision sling, are the most popular procedures for the treatment of stress urinary incontinence (SUI). Although the classical TOT procedure is a minimally invasive technique, we believe that this technique can be further improved.

Aim: To determine whether there was a difference in success and complication rates between the classical TOT technique and a novel technique called "modified transobturator tape" (mTOT), which avoids periurethral dissection.

Material and methods: In total, 98 patients who underwent incontinence surgery between July 2011 and January 2017 were recruited for this prospectively planned study. Of the 98 patients, 47 patients underwent classical TOT, and 51 patients underwent the new ITOT procedure. Incontinence Impact Questionnaire-7 (IIQ-7) and visual analogue scale (VAS) scores were obtained preoperatively and postoperatively. Average or serious symptomatic scores in IIQ-7 were considered as subjective failure.

Results: Nerve damage, vascular damage, retropubic hematomas, and bladder-urethra erosion were not observed in either group. There were no significant between-group differences in IIQ-7 scores. There were also no between-group differences in postoperative 1-month, 6-month, and 1-year VAS scores, but postoperative first day scores of the mTOT group were significantly lower than those of the classical TOT group $(p<0.05)$.

Conclusions: The proposed modified technique provides the same efficiency and reliability as the classic technique but is more advantageous in terms of reduced pain and resumption of earlier sexual activity.
\end{abstract}

Key words: urinary incontinence, incontinence surgery, transobturator tape, mid-urethral sling.

\section{Introduction}

Stress urinary incontinence (SUI) is a common disease in women, with $50-83 \%$ of women older than 65 years reported to be affected. In $6-10 \%$ of cases, SUI is estimated to be severe [1]. Mid-urethral slings, including transobturator tape (TOT), tension-free vaginal tape (TVT), tension-free vaginal tape-obturator (TVT-O), and a single incision sling, have been the most popular procedures for the treatment of
SUI for the last two decades [2]. Tension-free vaginal tape, which was first described by Ulmsten in 1996, had an $81 \%$ cure rate in an 11-year follow-up $[3,4]$. Complications, such as vascular injury, bladder perforation, and urinary retention, are rarely seen $[5,6]$. Prolene TOT insertion via the retropubic route was developed in 2001 and led to reduced morbidity [7]. Later, an inside-out TVT-O procedure (Gynecar; Ethicon, Inc., NJ, USA) was designed by Delava [8].

\section{Address for correspondence}

Özkan Onuk, Department of Urology, Yeniyüzyıl University, 26 Yılanlı Ayazma St, 34255 Istanbul, Turkey, phone: +90 902125439000,

e-mail: drozkanonuk@gmail.com 
Postoperative pain symptoms may be observed in both retropubic and TOT surgery. Although the location and duration of the pain can vary, it is often temporary and is generally felt in the thighs. According to the literature, there is no difference between TVT and TOT procedures in terms of pain intensity and frequency $[9,10]$. Although the classical TOT procedure is a minimally invasive technique, we believe that this technique can be further improved. Therefore, we describe a new technique called "modified TOT" (mTOT), which avoids periurethral dissection.

\section{Aim}

The aim of this study was to determine whether there was a difference in success and complication rates between the classical TOT procedure and $\mathrm{mTOT}$ procedure.

\section{Material and methods}

In total, 98 patients who underwent TOT surgery between July 2011 and January 2017 were recruited to this prospectively planned study after receiving approval of the local ethics board. The coin flipping randomization technique was used to assign modified or classical TOT status. Of these 98 patients, 47 patients underwent classical TOT, and 51 patients underwent the mTOT procedure. Preoperatively, patient histories were obtained, and all the patients underwent a physical examination, urine analyses, urine culture and antibiogram, the Marshall-Boney test, and the urethral Q-type test. All the patients completed a 24-h voiding diary and underwent urinary ultrasonography to determine the amount of post-voiding residue. Urodynamics was performed in mixed incontinence patients. All patients also completed the Incontinence Impact Questionnaire-7 (IIQ-7).

The exclusion criteria were previous incontinence surgery, known neurological diseases or findings, physical examination findings of above grade 1 pelvic organ prolapse in the Baden system, urethral mobility below $30^{\circ}$ in the Q-type measurement and below $60 \mathrm{cmH}_{2} \mathrm{O}$ in the leak point pressure measurement. IIQ-7 scores were obtained preoperatively and 1 month, 6 months, and 1 year after the surgery. Postoperative pain was evaluated using the visual analogue scale (VAS) score on the postoperative first day and at 1 months, 6 months and 1 year after surgery. Patients who underwent the classical TOT pro- cedure were allowed to engage in sexual intercourse after the fourth postoperative week versus the tenth postoperative day among those who underwent the mTOT procedure. Lack of urinary incontinence during the provocation test was considered objective recovery. Average or high IIQ-7 scores were considered subjective failure. All remaining conditions were evaluated as surgical success.

\section{Surgical procedure}

The surgical field was sterilized using povidone iodine, and a Foley urethral catheter was placed in the dorsal lithotomy position. After labial retraction, sutures were placed, and the surgical area was widened using a weighted vaginal speculum.

In alignment with the clitoris, $0.5 \mathrm{~cm}$ bilateral stab incisions were made inferior to the adductor longus muscle at the genitocrural fold level. Helical needles were inserted and passed through the obturator membrane. Without performing a vaginal incision, the ramus pubis and obturator internus muscles were identified with the index finger of the opposite hand. After locating these structures, the needle was traversed through the obturator membrane, obturator internus muscle, and periurethral endopelvic fascia until it was felt under the vaginal mucosa with the index finger. During this procedure, vaginal anterior wall damage was not observed. In the next step, the needle was pushed until it reached $1.5 \mathrm{~cm}$ below the urethral meatus (Photo 1 ). The same procedure was conducted for the opposite side, so that the needles met $1.5 \mathrm{~cm}$ below the urethral meatus (Photos 2 and 3). At this point, a $0.5 \mathrm{~cm}$ cut was made, and the needle points were taken outside (Photo 4). The synthetic sling material was attached to the needles, and the needles were backed out. The sling was then brought out through the level of the skin in the groin region. A surgical clamp was placed between the tape and urethra to control the tension. Excess sling material was cut out, and the incisions were closed with 4/0 fast-absorbing sutures. Cystourethroscopy was performed for the first 20 patients who underwent the modified technique. However, cystourethroscopy was later removed from the routine procedure, as no injury was observed. Vaginal tampons were used for the classical technique group to control bleeding but not for the modified technique group. Foley catheters of both groups as well as the vaginal tampons were 


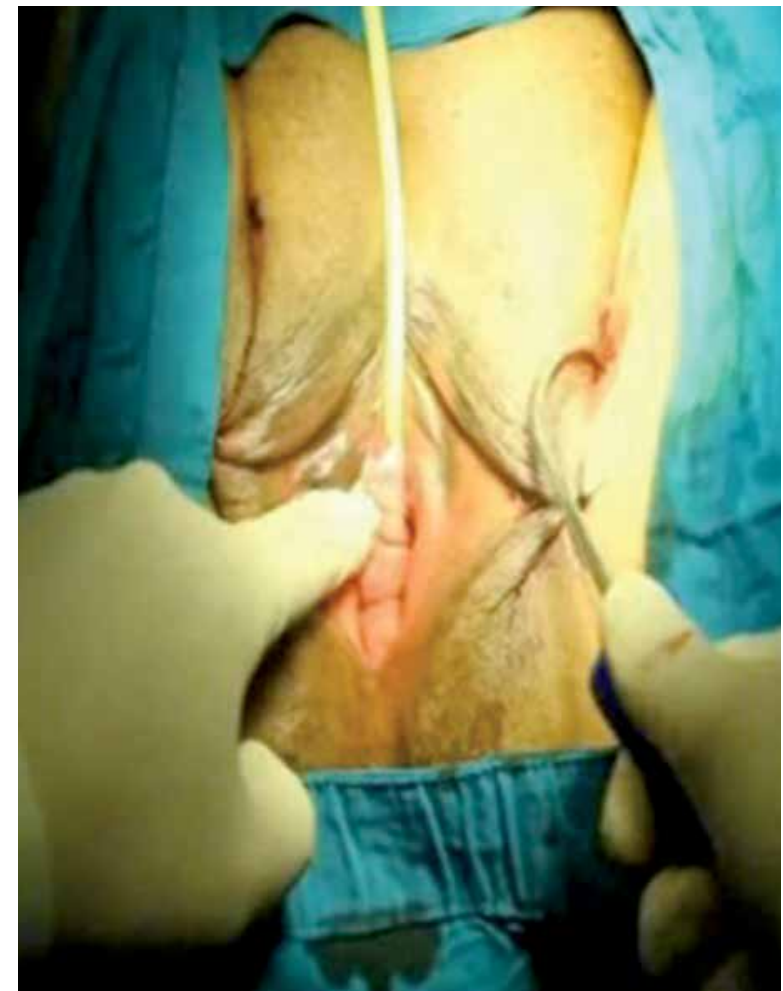

Photo 1 . The needle is pushed until it reaches $1.5 \mathrm{~cm}$ below the urethral meatus (left)

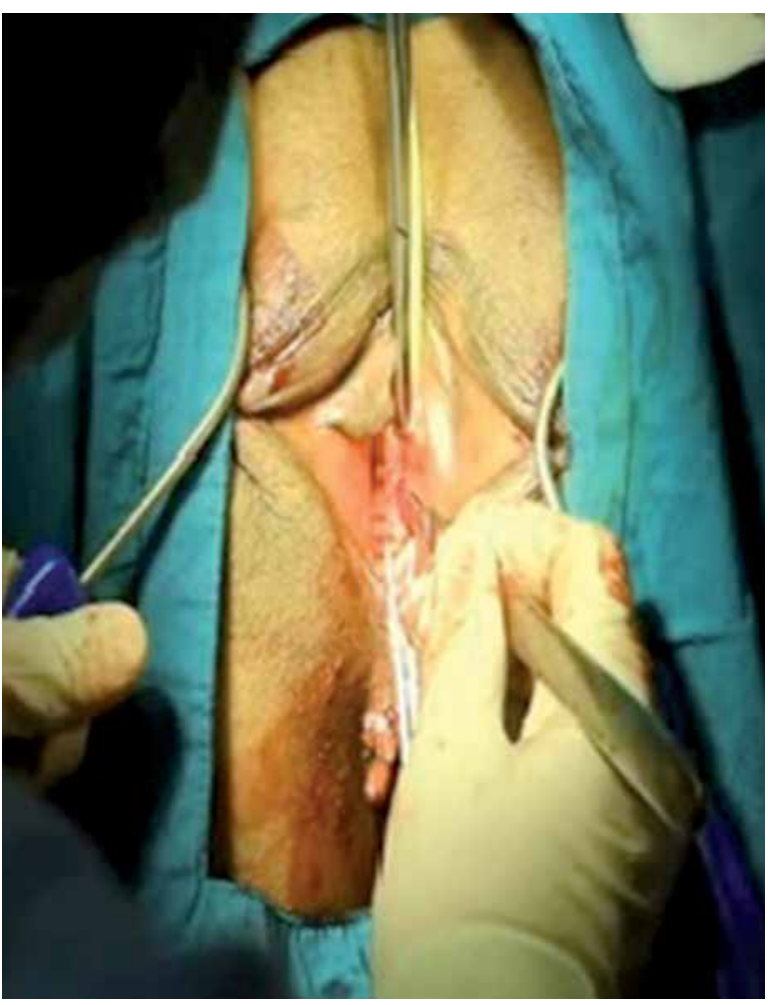

Photo 3. The needles meet $1.5 \mathrm{~cm}$ below the urethral meatus

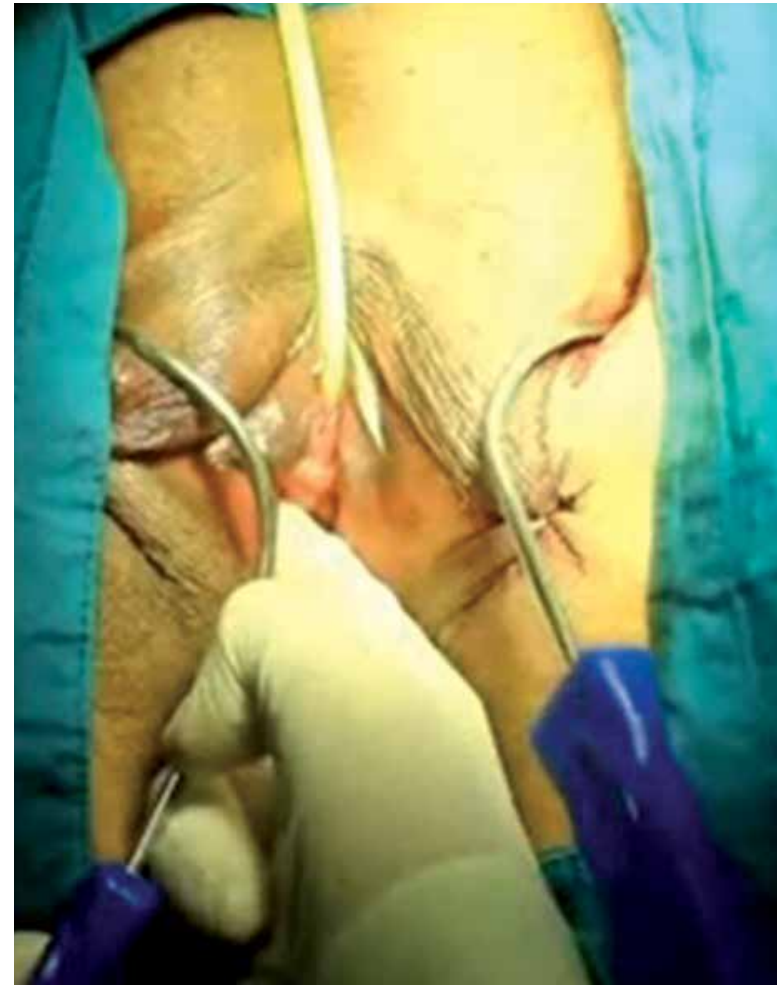

Photo 2. The needle is pushed until it reaches $1.5 \mathrm{~cm}$ below the urethral meatus (right)

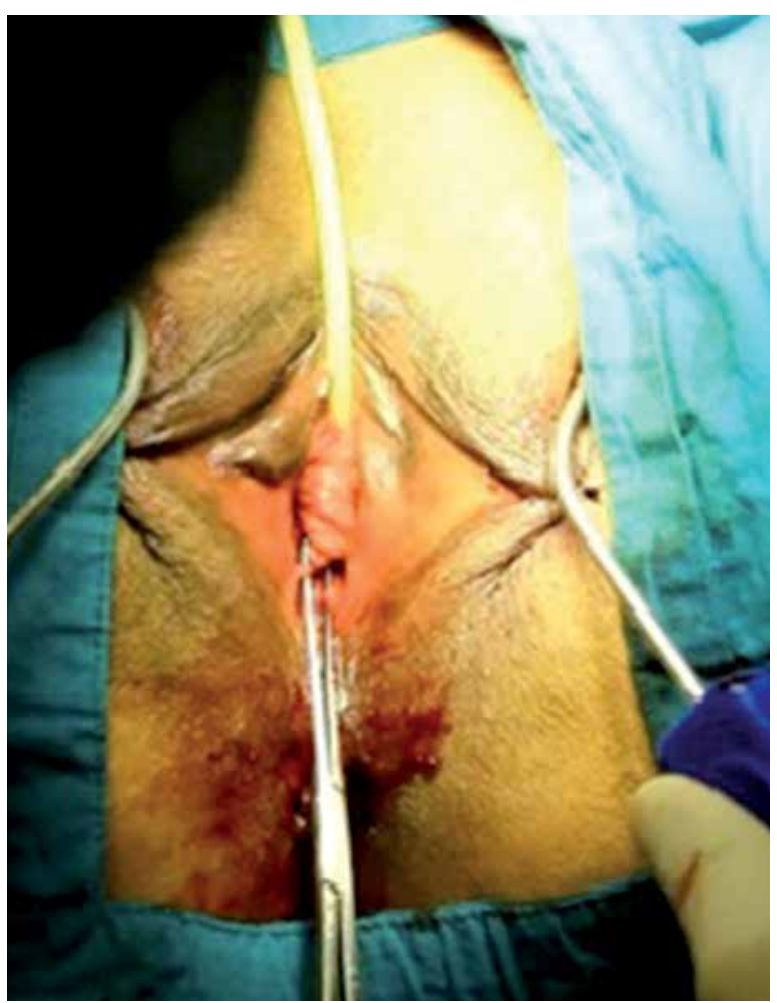

Photo 4. A $0.5 \mathrm{~cm}$ cut is made, and needle points are taken outside 
removed on the first postoperative day. All patients were discharged on the first postoperative day after confirmation post-void residual urine control.

\section{Ethical approval}

All procedures performed in studies involving human participants were in accordance with the ethical standards of the institutional and/or national research committee and with the 1964 Helsinki Declaration and its later amendments or comparable ethical standards.

Informed consent: Informed consent was obtained from all individual participants included in the study.

\section{Statistical analysis}

Numerical variables were expressed as median and quantitative variables as frequencies and percentages. The Shapiro-Wilk test was conducted to assess the conformity of the data to a normal distribution. Categorical variables were analyzed by the $\chi^{2}$ or Fisher's exact test, and continuous variables were analyzed by the Mann-Whitney $U$ test. Statistical analyses were performed using SPSS 21.0 (SPSS
Inc., Chicago, IL, USA), and $p<0.05$ was considered statistically significant.

\section{Results}

Demographic data of the classical TOT and mTOT groups are presented in Table I. There were no between-group differences in mean age, body mass index, parity, previous pelvic surgeries, menopausal status, presence of diabetes mellitus, and hypertension.

Postoperative complications are shown in Table II. Nerve damage, vascular damage, retropubic hematomas, and bladder-urethra erosion were not observed in either group.

There were no significant between-group differences in IIQ-7 scores (Table III).

Although there were no between-group differences in postoperative 1-month, 6-month, and 1-year VAS scores, the postoperative first day scores of the mTOT group were significantly lower than those of the classical TOT group $(p<0.05)$ (Table IV).

\section{Discussion}

Since the publication of Ulmstein's study in 1996, various mid-urethral sling technologies have

Table I. Patients' characteristics in classical and modified TOT groups

\begin{tabular}{|lccc|}
\hline Parameter & Classical TOT & Modified TOT & $P$-value \\
\hline Age, median & $53(37-67)$ & $56(33-67)$ & 0.21 \\
\hline Body mass index $\left[\mathrm{kg} / \mathrm{m}^{2}\right]$ & $31(25-40)$ & $33(24-41)$ & 0.63 \\
\hline Parity, $n$ & $3(2-5)$ & $2(1-5)$ & 0.13 \\
\hline Previous pelvic surgery, $n(\%)$ & $6(19.4)$ & $5(18.5)$ & 0.89 \\
\hline Menopause, $n(\%)$ & $21(67.7)$ & $19(70.4)$ & 0.92 \\
\hline DM, $n(\%)$ & $9(29)$ & $8(29.6)$ & 0.88 \\
\hline HT, $n(\%)$ & $9(29)$ & $8(33.3)$ & 0.95 \\
\hline
\end{tabular}

$D M$ - diabetes mellitus, $H T$ - hypertension; * significance level is $p<0.05$.

Table II. Postoperative complications

\begin{tabular}{|lccc|}
\hline Variable & Classical TOT & Modified TOT & P-value \\
\hline Inguinal pain & 3 & 1 & 0.12 \\
\hline Urinary retention & 1 & 0 & 0.91 \\
\hline Dyspareunia & 1 & 2 & 0.26 \\
\hline Urgency & 2 & 5 & 0.88 \\
\hline Total & 7 & 0.72 \\
\hline
\end{tabular}


Table III. Changes between preoperative and postoperative scores of IIQ-7

\begin{tabular}{|lccc|}
\hline Variable & Classical TOT & Modified TOT & $P$-value \\
\hline IIQ-7 Preop. & $10(7-5)$ & $9(7-15)$ & 0.74 \\
\hline$\| \mathrm{IQ}-71^{\text {st }}$ month & $1(0-3)$ & $1(0-3)$ & 0.78 \\
\hline$\| \mathrm{II}-76^{\text {th }}$ month & $1(0-3)$ & $1(0-2)$ & 0.89 \\
\hline$\| \mathrm{I}-71^{\text {st }}$ year & $1(0-2)$ & $1(0-2)$ & 0.81 \\
\hline
\end{tabular}

Statistical significance $p<0.05$.

Table IV. Comparison of postoperative VAS scores of two groups

\begin{tabular}{|lccc|}
\hline Variable & Classical TOT & Modified TOT & $P$-value \\
\hline VAS $1^{\text {st }}$ day & $4(0-6)$ & $2(0-4)$ & $<0.05$ \\
\hline VAS ${ }^{\text {st }}$ month & 1 & 1 & 0.26 \\
\hline VAS 6 ${ }^{\text {th }}$ month & 0 & 0 & - \\
\hline VAS ${ }^{\text {st }}$ year & 0 & 0 & - \\
\hline${ }^{*}$ Statistical significance $p<0.05$ & & &
\end{tabular}

been used. In the last decade, urethral-type synthetic slings have been used in $83.9 \%$ of all incontinence surgery procedures, and $26.9 \%$ of these employed the TOT technique [11]. Although techniques for SUI treatment were successful, modified techniques were developed with the aim of obtaining better outcomes, such as reduced morbidity and increased rates of success. In 2009, Lee et al. [12] described the use of a new surgical technique, canal TOT, and Long et al. [13] described the use of another technique, modified prepubic TVT, in 2013 [13]. The results of their studies revealed no superiority between the new techniques when compared with those of classic techniques $[12,13]$. In the present study, postoperative pain was significantly lower in the mTOT group on the first postoperative day as compared with that in the classic TOT group. The pain scores of the two groups were not significantly different at postoperative 1 month, 6 months, and 1 year.

The TOT technique described by Delorme et al. in 2001 [7] is preferred due to its ease of use and rapid application. Moreover, intraoperative complication risks are considered to be lower using the TOT technique of Delorme et al. than TVT and modified TVT techniques. The TVT procedure poses a higher risk of bladder, bowel, urethral, and vascular injuries than the TOT procedure, although the success rates with the two procedures are similar [14]. In addition, complications, such as bladder perforation, urethral injury, and retropubic hematomas, have been report- ed in TOT operations. Surgeons who have experience of such complications suggest that creating a wide tunnel enough for the surgical finger and pushing the needle with the guidance of this finger can decrease the risk of complications. However, this method may damage the neurovascular function of the periurethra, and wide dissection may hinder proper placement of the sling material $[4,5]$. Furthermore, after the sling material is placed, it may migrate to distal or proximal areas [15-19]. In the proposed technique described herein, the needle is pushed with the guidance of a finger, feeling it into the submucosa, without performing a dissection. Due to the avoidance of paraurethral dissection and the placement of the sling material at the appropriate level, the migration risk of the sling material to the bladder neck or another location is removed.

Schierlitz et al. [20] studied patients with intrinsic sphincter deficiency and divided them into TOT and TVT groups. Within a 3-year follow-up time, 20\% of patients who underwent TOT procedures required further surgery, whereas this figure was only $1.4 \%$ in the TVT group. Several reasons have been put forward to explain the difference in outcomes between the two techniques. Firstly, when the sling material is placed during the TVT procedure, the pelvic fascia may be perforated. Secondly, the non-dissected area is longer, which allows better localization and prevents migration of the sling material. As our technique avoids dissection and prevents migration of 
the material, we believe that its success rate may be close to that of TVT for patients with intrinsic sphincter deficiency.

Patients who underwent the classical TOT procedure were allowed to engage in sexual intercourse after the fourth postoperative week as compared with the tenth postoperative day for patients who underwent the mTOT procedure. In this study, mTOT patients reported less dyspareunia after early sexual activity. The resumption of earlier sexual activity due to the lack of introital wound tenderness is another advantage of our technique.

\section{Conclusions}

This modified technique provides the same efficiency and reliability as the classic technique, but is more advantageous in terms of pain reduction and resumption of earlier sexual activity. The limitations of this study were the small number of patients, and the patient groups were not randomly selected. Additional studies, with longer-term follow-ups may provide more insights into the effects of the mTOT procedure.

\section{Conflict of interest}

The author declares no conflict of interest.

\section{References}

1. Nygaard I, Turvey C, Burns TL, et al. Urinary incontinence and depression in middle-aged United States woman. Obstet Gynecol 2003; 101: 149-56.

2. Kennelly MJ, Moore R, Nguyen JN, et al. Miniarc single-incision sling for treatment of stress urinary incontinence: 2-year clinical outcomes. Int Urogynecol J 2012; 23: 1285-91.

3. Petros PE, Ulmsten UI. An integral theory and its method for the diagnosis and management of female urinary incontinence. Scand J Urol Nephrol Suppl 1993; 153: 1-93.

4. Nilsson CG, Palva K, Rezapour M, Falconer C. Eleven years prospective follow-up of the tension-free vaginal tape procedure for treatment of stress urinary incontinence. Int Urogynecol J Pelvic Floor Dysfunct 2008; 19: 1043-7.

5. Meschia M, Pifarotti P, Bernasconi F, et al. Tension-free vaginal tape: analysis of outcomes and complications in 404 stress incontinent women. Int Urogynecol J Pelvic Floor Dysfunct 2001; 12 (Suppl 2): 24-7.

6. Long CY, Lo TS, Liu CM, et al. Lateral excision of tension-free vaginal tape for the treatment of iatrogenic urethral obstruc tion. Obstet Gynecol 2004; 104: 1270-4.

7. Delorme E. Transobturator urethral suspension: mini-invasive procedure in the treatment of stress urinary incontinence in women. Prog Urol 2001; 11; 1306-13.
8. De Leval J. Novel surgical technique for the treatment of female stress urinary incontinence: transobturator vaginal tape inside-out. Eur Urol 2003; 44: 724-30.

9. Ogah J, Cody JD, Rogerson L. Minimally invasive synthetic suburethral sling operations for stress urinary incontinence in women. Cochrane Database of Syst Rev 2009; 7: CD006375.

10. Debodinance P. Trans-obturator urethral sling for surgical correction of female stress urinary incontinence: outside-in (Monarc) versus inside-out (TVT-O). Are both ways safe? J Gynecol Obstet Biol Reprod 2006; 35: 571-7.

11. Galmes Belmonte I, Diaz Gomez E. The devices used to correct the urinary incontinence by tension-free meshes. Are all them equals? Actas Urol Esp 2004; 28: 487-96.

12. Lee JH, Yoon HJ, Lee SJ, et al. Modified transobturator tape (canal transobturator tape) surgery for female stress urinary incontinence. J Urol 2009; 181: 2616-21.

13. Long CY, Wu MP, Wang CL, et al. Modified prepubic TVT-obturator tape procedure versus the conventional method: a preliminary study. Eur J Obstet Gynecol Reprod Biol 2013; 171: 376-80.

14. Andonian S, St-Denis B, Lemieux MC, Corcos J. Prospective clinical trial comparing Obtape and DUPS to TVT: one-year safety and efficacy results. Eur Urol 2007; 52: 245-51.

15. Costa P, Grise P, Droupy S, et al. Surgical treatment of female stress urinary incontinence with a transobturator-tape (T.O.T.) Uratape: short term results of a prospective multicentric study. Eur Urol 2004; 46: 102-6.

16. Minaglia S, Ozel B, Klutke C, et al. Bladder injury during transobturator sling. Urology 2004; 64: 376-7.

17. Smith PP, Appell RA. Transobturator tape, bladder perforation, and paravaginal defect: a case report. Int Urogynecol J Pelvic Floor Dysfunct 2007; 18: 99-101.

18. Rajan S, Kohli N. Retropubic hematoma after transobturator sling procedure. Obstet Gynecol 2005; 106: 1199-202.

19. Poon C, Zimmern P. When the sling is too proximal: a specific mechanism of persistent stress incontinence after pubovaginal sling placement. Urology 2004; 64: 287-91.

20. Schierlitz L, Dwyer PL, Rosamilia A, et al. Three-year follow-up of tension-free vaginal tape compared with transobturator tape in women with stress urinary incontinence and intrinsic sphincter deficiency. Obstet Gynecol 2012; 119: 321-7.

Received: 16.03.2018, accepted: 13.07.2018. 